\title{
ARQUEOLOGÍA DE LA PAIDEIA. LAS SEDES DE LA EDUCACIÓN SUPERIOR EN LAS PROVINCIAS HELENÍSTICAS DEL IMPERIO (II): TEMPLOS, SANTUARIOS, MUSEOS, BIBLIOTECAS, AUDITORIOS, TEATROS Y BOULEUTERIA*
}

\author{
Jorge García Sánchez \\ Universidad Complutense de Madrid \\ jorgegar@pdi.ucm.es
}

\section{ARCHAEOLOGY OF THE PAIDEIA. HIGHER EDUCATIONAL CENTERS IN THE HELLENISTIC PROVINCES OF THE EMPIRE (II): TEMPLES, SANCTUARIES, MUSEUMS, LIBRARIES, AUDITORIUMS, THEATERS AND BOULEUTERIA}

RESUMEN: Durante la época imperial distintos edificios se destinaron a la formación educativa de la juventud, a pesar de que en ocasiones su funcionalidad original fuera otra. Hasta la Antigüedad tardía, profesores y alumnos, oradores y sus públicos, filósofos y prosélitos, desarrollaron sus actividades en auditorios, teatros, salas de consejo, santuarios, museos o templos. Con un mayor intervencionismo estatal en materia didáctica, algunas de estas sedes se reservaron a los docentes de elección imperial o de la curia de la ciudad. Posiblemente el surgimiento de una nueva tipología arquitectónica relacionada con la educación, la de los auditorios, se encuentre ligado a ese control de la formación de sus súbditos por parte del poder romano.

PALABRAS CLAVE: Asclepieia, Alejandría, Museos, Auditorios de Kôm el-Dikka, Athenaeum de Adriano.

\begin{abstract}
During the Roman Empire, different kinds of buildings were used to provide educational training for young people. Until Late Antiquity, teachers and students, public speakers and audiences, and philosophers and proselytes developed their activities in auditoriums, theaters, bouleuteria, sanctuaries, museums, and temples. When Rome took charge of education, several of these places were reserved for official teachers of imperial and municipal choosing. The emergence of a new building typology related to education, the auditorium, is possibly linked to Rome's desire to control what its subjects learned.
\end{abstract}

KEYWORDS: Asclepieia, Alexandria, Museums, Auditoria of Kôm el-Dikka, Adrian Athenaeum.

RECIBIDO: 27.05.2013. ACEPTADO: 01.05.2014

* El segundo artículo dedicado a los centros de la educación superior en el Oriente romano ha nacido, al igual que el anterior, dentro del proyecto del Ministerio de Economía y Competitividad HAR2010-18915. 
A mediados del siglo IV d.C., cuando el retórico Libanio se asentó en su Antioquía natal a fin de fundar una escuela privada dedicada a la enseñanza, entre otras materias, de la oratoria, se le aconsejó que para atraer a aquellos conciudadanos sedientos de saber habría de asentarse en algún templo. Como sede consonante a las actividades que pretendía desarrollar no le resultaba una novedad, pues poco antes, entre el 344 y el 349 d.C., buena parte de sus clases se habían celebrado en el templo de la Fortuna de Nicomedia -a la vez que en la sala del consejo o boulé-, cuando gozaba del apoyo del gobernador de Bitinia y sus conferencias le cosechaban no sólo aplausos sino un proficuo alumnado ${ }^{2}$. Recién llegado a la ciudad del Orontes, sin embargo, y privo de un puesto de sofista municipal, se lamentaba de la posición de privilegio de la que disfrutaban los profesores que ocupaban el Museo, y precisamente desde el pórtico del templo de las Musas, se desahogaba en dirección del altar de Calíope por el "castigo" que le obligaba a limitar sus lecciones al ámbito privado. El Museion había jugado un papel fundamental en la vida cultural de la antigua capital seleúcida, por lo que relata el cronista bizantino Iohannes Malalas: edificado en época helenística, a la par que una biblioteca, con los fondos donados en su testamento por Marón de Antioquía, Marco Aurelio lo había reconstruido, decorándolo con un magnífico mosaico, después de que el devastador incendio del 23 d.C. lo destruyese junto al mercado y al bouleuterion. A finales del siglo III d.C. se tienen noticias de que el emperador Probo lo ornamentó profusamente, y de que en dicho ninfeo situó un mosaico con la imagen de Okeanos, que a partir de entonces dio nombre al monumento ${ }^{4}$. Gracias a la promoción de Libanio a una plaza oficial de sofista encontramos que no fue el recinto cultual de las Musas -desde el 335 d.C. convertido en el praetorium del prefecto del pretorio Feliciano, elección que manifiesta la relevancia y majestuosidad del edificio ${ }^{5}$-, ni el de Fortuna o Tyche el que acogía a sus estudiantes, o los certámenes oratorios ${ }^{6}$, sino el bouleuterion, asiento de la curia antioqueña. De esto informaba al orador Leoncio en una misiva fechada en el 359 d.C.?: "pues el templo de Fortuna, noble Leoncio, está privado de todo su esplendor y de los rebaños que un día apacentaba, lo que hace derramar lágrimas cada vez que paso cerca"s.

\footnotetext{
'Lib. Or. 1.102.

${ }^{2}$ Lib. Or. $1.51 ; 1.72$.

${ }^{3}$ Lib. Or. 1.102.

${ }^{4}$ Io.Mal. Chron. 10.235, 236; 11.282; 12.302.

${ }^{5}$ Io.Mal. Chron. 13.319.

${ }^{6}$ En ocasión de una de las declamaciones de Libanio, algunos espectadores habían dormido alli para poder escucharle. Lib. Or. 1.87.

${ }^{7}$ El bouleuterion de Antioquía aparecía dotado de un theatron, un graderío desde el cual los estudiantes escuchaban las lecciones de Libanio, impartidas desde su asiento, el thronos, así como de un patio porticado convertido en jardín. R. Cribiore, The School of Libanius in Late Antique Antioch (Prin-

${ }^{8}$ Lib. Ep. 88.2 .
} ceton-Oxford 2007) 44. 
El ejemplo de Libanio deja patente la multiplicidad de ambientes en los que la actividad docente se podía desarrollar, así como la mayor o menor categoría de unos establecimientos frente a otros: en términos cualitativos, por la oficialidad de la función practicada en ellos -aparejada a su consiguiente prestigio social-, y cualitativos, de atracción del alumnado. Más adelanté insistiré en qué grado llegaría a ser o no determinante que la oficialidad del cargo pedagógico desempeñado a nivel local, a la par que el control estatal, influyeran en la estabilización de la labor didáctica en unos u otros centros determinados, e incluso en la creación de innovadoras tipologías edilicias capaces de responder a la creciente demanda de los servicios educativos. Baste por ahora reseñar que cronológicamente se trata de un fenómeno tardío (aunque detectable en algunos casos a partir del siglo II d.C.), dado que en fechas anteriores encontramos que sólo excepcionalmente los emperadores desplegaron una verdadera política inherente a la educación pública, pues la enseñanza superior, por lo normal, se confiaba a la iniciativa privada. A Vespasiano se le atribuye inaugurar cierta injerencia desde el poder hacia el 71 d.C., al haber destinado 100.000 sestercios del erario para fijar un sueldo, y por tanto garantizar una posición, a sendos maestros de retórica griega y latina en Roma; pocos años después extendió las mercedes hacia este sector al declarar exentos de impuestos a gramáticos y rectores, y también en un sentido geográfico, dado que viene atestiguado por una inscripción encontrada en Pérgamo9. Pero acciones similares no se retomaron hasta el siglo siguiente y siempre dependieron del interés depositado por el emperador de turno en las cuestiones pedagógicas. Veamos ahora la diversidad de centros en los que éstas tuvieron lugar, comenzando por las sedes religiosas.

La educación que residía en los templos, en mayor o menor grado reglada, parece haber afectado al rango de edad que iniciaba hacia los trece años, los cuales, en estimaciones de Raffaella Cribiore, serían los que tenían la mayoría de alumnos que se embarcaban en los estudios de la oratoria con Libanio ${ }^{10}$. Así se ratifica en Filóstrato, quien en su breve biografía de Hipódromo de Tesalia apuntaba que el sofista localizó una escuela local de Esmirna al toparse delante de un templo con un grupo de paides acompañados de sus correspondientes pedagogos y esclavos cargados de libros, que asistían a las clases de Megistias. Allí mismo, en su interior, acomodado en un sitial, el tesalio declamó ante el ilustre profesor ${ }^{11}$. Dentro de los límites cronológicos del Imperio no tan sólo poseemos referencias de la utilización de estructuras religiosas como centros estables con fines pedagógicos para los siglos de la Tardoantigüedad: de resultar fiables las palabras de Filóstrato acerca de Apolonio de Tiana (3- c.97 d.C.), en su juventud se adhirió a los principios pitagóricos que, al mismo tiempo que las filosofías platónica, epicúrea,

${ }^{9}$ M. Joyal, I. McDougall, J. C. Yardley, Greek and Roman Education. A Sourcebook (London 2009) 229 y 230.

${ }^{10}$ R. Cribiore, op. cit. 31.

${ }^{11}$ Philostr. VS. 2.27.618. 
peripatética y estoica, se impartían en el Asclepieion de Egas (Acaya). Aquí fijó su hogar después de renunciar a los alimentos impuros y al consumo del vino, se ganó a sus primeros admiradores, ayudó al dios con sus actividades sanadoras y, cumplidos los veinte años de edad, hizo del templo de Asclepio su Liceo y su Academia, en palabras de su biógrafo ${ }^{12}$.

En una enorme variedad de situaciones didácticas y coyunturas tanto sociales como religiosas, templos y santuarios acogían a filósofos y a sofistas durante largos periodos de tiempo a fin de que mostrasen ante concurridas audiencias sus artes. Incluso los propios retóricos del lugar llevaban a cabo sus recitaciones en eventos ciudadanos de acceso público como complemento a la instrucción estándar recibida por los discípulos en las aulas ${ }^{13}$. Cualquier oportunidad resultaba adecuada para que un orador profesional se detuviera en la ciudad: con motivo de festividades, de la celebración de misterios, de desfiles procesionales, con ocasión de inauguración de monumentos, de visitas oficiales, de sacrificios y de libaciones públicas ${ }^{14}$. Declamadores procedentes de todo el mundo heleno convergían en los grandes santuarios de Delfos, o de Olimpia, con objeto de poner a prueba sus habilidades en público. La costumbre de viajar por parte de los intelectuales, en especial en ese siglo II d.C. caracterizado por la edad dorada de la publicitación de la paideia helena, resultaba una necesidad para los profesionales de la palabra ${ }^{15}$. La adición de actuaciones retóricas de éxito difundía su notoriedad de población en población -con repercusiones a nivel provincial e incluso extra-provincial-, sumaba acólitos a su persona y los ponía en contacto con las élites y las figuras eruditas municipales, además de conferirles un estatus de superioridad social, que en muchos casos ya poseían por nacimiento. Los parlamentos impartidos, improvisados o compuestos previamente, y de forma habitual entroncados con acontecimientos y épocas de esplendor del pasado griego, contenían una buena dosis de interactuación con los espectadores presentes, con sus reacciones, aspiraciones, criterios y aficiones, e incluso con el lugar físico donde se efectuaran ${ }^{16}$. Y los beneficiados de esas lecciones populares de Historia y de mitología, de virtudes filosóficas, de concienciación moral, a menudo de loa de la urbe de acogida, no únicamente eran los autóctonos, sino que multitudes de asistentes recorrían largas distancias a fin de escuchar a los sofistas de moda. Narra Filóstrato que jóvenes provenientes de Beocia, de la Fócide, de la Élide, de Tesalia, Argos, Esparta, Corinto, y de Atenas, los estudiantes de todas las tierras que residían en la capital ática, afluyeron en masa a escuchar al citado Apolonio de Tiana a lo largo de los cuarenta días que permaneció declamando desde

\footnotetext{
${ }^{12}$ Philostr. VA. 1.154, 156, 158.

${ }^{13}$ J. W. H. Walden, The Universities of Ancient Greece (London 1913) 221.

${ }^{14}$ M. Pretzler, "Greeks Intellectuals on the Move: Travel and Paideia in the Roman Empire", C. Adams (ed.), Travel, Geography and Culture in Ancient Greece, Egypt and the Near East (Oxford 2007) 129.

${ }^{15}$ Los centros cívicos que congregaron a los sofistas en el siglo II d.C. han sido bien estudiados en G. W. Bowersock, Greek Sophists in the Roman Empire (Oxford 1969) 17-29.

${ }^{16}$ T. Whitmarsh, The Second Sophistic (Oxford 2005) 24-26.
} 
la terraza del templo de Zeus de Olimpia, así como que frente a la estatua crisoelefantina de Fidias interrogaba a quienes deseaban convertirse en sus discípu$\operatorname{los}^{17}$. En Éfeso se dirigió a la multitud en el templo de Artemisa, en el teatro y en los bosquecillos que rodeaban las pistas de los gimnasios ${ }^{18}$. Una popularidad similar lograría en sus tours, en los cuales le acompañaba una corte de seguidores (a sus discípulos más cercanos se los conocería como los "apolónicos") en peregrinaje e investigación anticuaria por los santuarios helenos de Dodona, de Delfos, de Trofonio en Libadia, de las Musas en el monte Helicón, de Asclepio en Pérgamo, por las tumbas de los héroes homéricos, si bien su deambular le condujo por otras diversas regiones del orbe ${ }^{19}$. Este modelo de educación itinerante (el ejemplo más clara de la irradiación de la paideia) focalizada en los grandes santuarios, cercano a un turismo de élite, respondía, en paralelo que a las aspiraciones de obtener fama, repercusión "mediática" y concurso de público, a las inquietudes espirituales que sintiese el propio sofista, y a su necesidad de exteriorizar determinadas creencias religiosas en un contexto sagrado ${ }^{20}$. El maestro de la elocuencia Elio Aristides (117-195 d.C.) adoptó durante años las prescripciones sanadoras, regímenes, ayunos y desplazamientos que Asclepio le impuso en su santuario de Pérgamo, divinidad que además alentaba a Aristides a proseguir el curso normal de sus prácticas oratorias, a pesar de sus enfermedades. El 145 y el 146 d.C. que transcurrió allí fueron años de una ferviente producción intelectual, de un fluido intercambio de ideas, de lecturas, con los sofistas y filósofos que al igual que él esperaban las consignas del dios, y practicaban sus discursos comunicándoselos unos a otros en los propileos y porticados del $\mathrm{As}$ clepieion $^{21}$. Sabemos de la participación de Polemón de Laodicea, de Hermócrates de Focea y de Antíoco de Egas en esa comunidad pergamena no sólo fiel a los consejos pronunciados por Asclepio durante el sueño, sino a la comunicación entre pensadores ${ }^{22}$. Los peregrinos, incubantes y habitantes de la ciudad se reunían en los edificios sacros, el odeón y el bouleuterion cuando se autorizaban mediante decreto las conferencias en ellos; contemporáneamente podía tener lugar más de una intervención ${ }^{23}$, pero en un mismo local gozaban de la precedencia los sofistas de la juventud autóctona ${ }^{24}$. La mitificación de las figuras de la retórica incitaba además que se les atribuyese la realización de gestas milagrosas y que sus existencias se poblasen de hechos fabulosos, de modo que se esperaba de

\footnotetext{
${ }^{17}$ Philostr. VA. 8.382-383.

${ }^{18}$ Philostr. VA. 4.234-236; 8.389.

${ }^{19}$ Véase J. Elsner, "Hagiographic Geography: travel and allegory in the Life of Apollonius of Tyana", JHS CXVII (1997) 22-37.

${ }^{20}$ M. Pretzler, op. cit. 134-135.

${ }^{21}$ Aristid. Or. 4.17-18.

${ }^{22}$ Philostr. VA. $1.25 ; 2.4 ; 2.25$.

${ }^{23}$ Es bien conocida la ocasión en que Aristides (Or. 5.30-34) impartió una conferencia en la abarrotada sede del consejo, mientras que paralelamente un sofista egipcio, que había manipulado a algunos notables para obtener el permiso de declamar, únicamente reunió a diecisiete personas en el odeón.

${ }^{24}$ Aristid. Or. 5.38 .
} 
ellos el ejercicio de sus capacidades sobrenaturales en las visitas a las localidades de atracción litúrgica, propias de individuos fuera de lo normal. Así, de Máximo de Éfeso (310-372 d.C.) recordaba Eunapio cómo asombró a sus condiscípulos y demás ciudadanos pergamenos presentes en el templo de Hécate al inducir a la carcajada a la estatua de la diosa mediante una serie de ritos ${ }^{25}$, y a Apolonio incluso se le consagró un santuario en Tiana, en reconocimiento de sus poderes prodigiosos $^{26}$. La obra de Filóstrato, en efecto, se orienta a acentuar la autoridad y la preponderancia del pensador cario en ese mundo salpicado de episodios portentosos, de sabios y de filósofos cosmopolitas ${ }^{27}$.

Sobre todo los Asclepieia, como se va perfilando, fueron santuarios de una enorme popularidad desde el siglo V a.C. hasta el Bajo Imperio (varios de ellos a nivel panhelénico) como lugares que más allá de sus implicaciones curativas garantizaban ciertas prestaciones académicas ${ }^{28}$. Aparte de las de filosofía, diferentes testimonios señalan su funcionalidad como escuelas de medicina, derivada de las posibilidades empíricas que otorgaba la pluralidad de enfermos implorando al dios sanador ${ }^{29}$. En Pérgamo, Cos (en él se había formado Hipócrates), Esmirna o Cíbira los estudiantes completaban los rudimentos básicos de anatomía que seguramente habían recibido en el medio familiar, típicos de una disciplina transmitida oralmente ${ }^{30}$ (fig. 1). Y, a tono con las enseñanzas metafísicas que los discípulos aprendían en los templos de Asclepio, y como una rama más de la filosofía, la adhesión a una secta médica, caracterizada por sus métodos y teorías particulares (las escuelas más usuales eran la empírica, la dogmática, y la metódica), resultaba indispensable. La carrera de Galeno (130-c. 200 d.C.), por ejemplo, fraguó en dos de las urbes anotadas, entre su Pérgamo natal, donde su padre Nicón le inculcó la geometría, el cálculo, la aritmética, y se interesó porque se formara en la medicina en el Asclepieion, y Esmirna, bajo la tutela del dogmático Pélope y del platónico Albino; pero asimismo concluyó una etapa de aprendizaje de doce años de duración en Alejandría, Corinto y Roma ${ }^{31}$. Incluso escribe Catia Trombetti que en el origen de las sedes de la educación por excelencia, los

${ }^{25}$ Eun. VS. 7.

${ }^{26}$ Philostr. VA. 8.392.

${ }^{27}$ J. Elsner, art. cit. 24 y 25.

${ }^{28}$ Algunas generalidades sobre los Asclepieia se pueden consultar en M. López Pérez, "Los Asclepeia, templos de curación y centros de peregrinación en la Antigüedad”, G. Bravo, R. González Salinero (eds.), Ver, viajar y hospedarse en el mundo romano (Madrid-Salamanca 2012) 137-149.

${ }^{29}$ Según Plinio el Viejo, la ciencia médica no sólo habría sido fundada por Hipócrates gracias a la costumbre de que en los Asclepieia, como el de Cos, los enfermos dejaran por escrito la composición del remedio que los había ayudado, a fin de que se reprodujera e tratamiento en casos análogos. R. Frasca, Educazione e formazione a Roma. Storia, testi, immagini (Bari 2011) 475.

${ }^{30}$ M. Sartre, El Oriente romano. Provincias y sociedades provinciales del Mediterráneo oriental, de Augusto a los Severos (31 a. de C.-235 d. de C.) (Madrid 1994) 198; J. Jouanna, "Il medico tra tempio, città e scuola", S. Settis (ed.), I. Greci. Storia, Cultura, Arte, Società. 2. Un storia greca. II Definizione (Torino 1997) 803.

${ }^{31}$ Léase la introducción de T. Martínez Manzano a Galeno, Tratados filosóficos y autobiográficos (Madrid 2002) 11. 


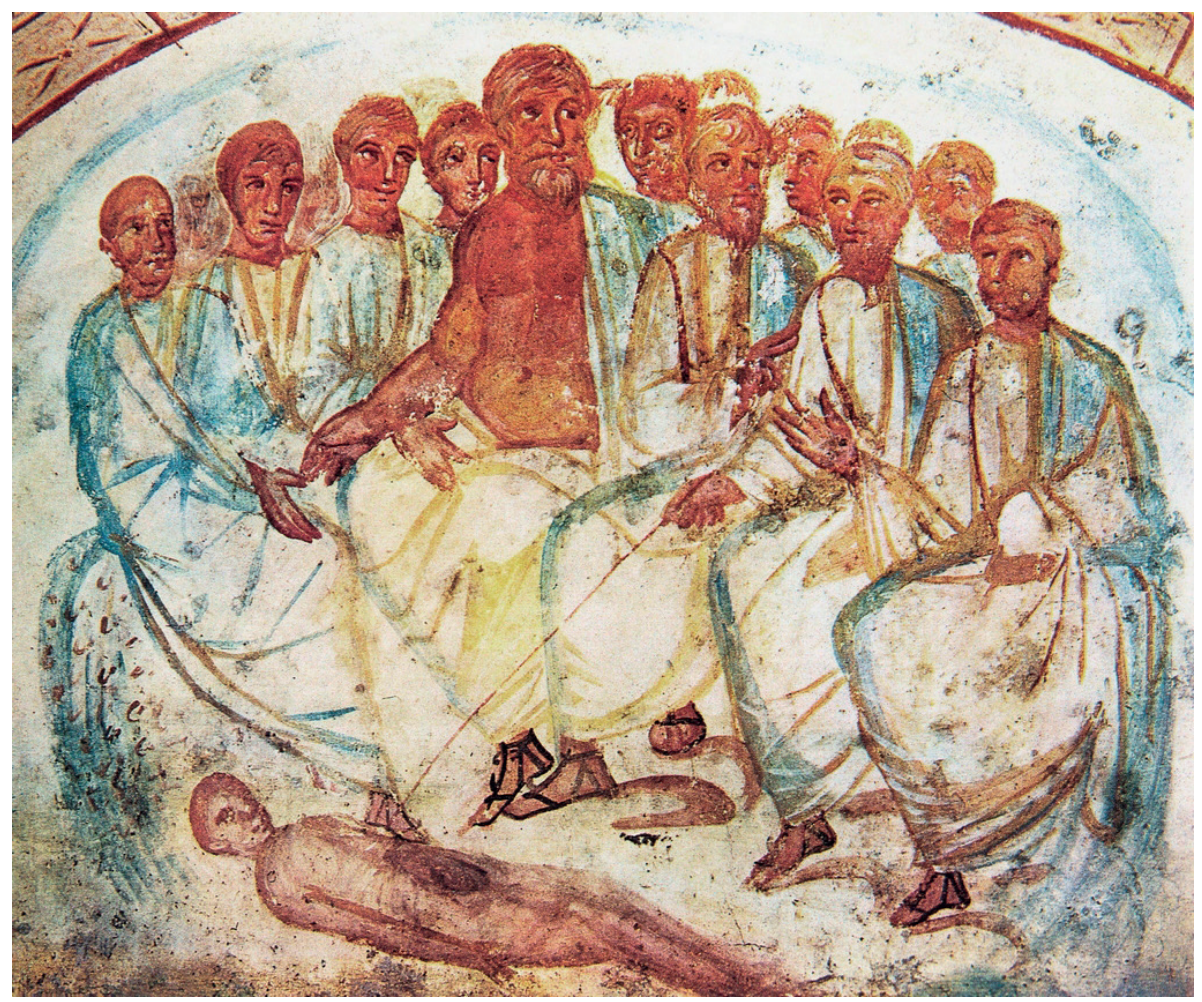

Figura 1. Lección de anatomía, s. IV d.C. Roma, Catacumbas de la Vía Latina

gimnasios, y como alentadores de su mismo alzamiento, se detecta el trasfondo de los cultos heroicos y funerarios, y la veneración de las figuras divinas. Desde el punto de vista topográfico, en los gimnasios de Corinto y de Asopo encuentra una correlación ritual con el Asclepieion (en el interior del segundo se han descubierto reliquias dedicadas al dios) que le persuaden de una dependencia que supera la mera piedad habitual dentro de estas instituciones, y que traslada al hecho fundacional ${ }^{32}$. Que los templos consagrados al dios de la medicina se localizaran, además, dentro de los gimnasios, no sería una eventualidad infrecuente, según se lee en Elio Aristides y en Filóstrato para el caso de Esmirna, cuando la estrecha vinculación de Asclepio con el ámbito pedagógico se estrechara todavía más a partir de época romana, al actuar el divino hijo de Apolo como protector del ejercicio físico ${ }^{33}$.

${ }^{32}$ C. Trombetti, "Ginnasi come santuari. Il Peloponneso", Siris 7 (2006) 53, 54 y 67.

${ }^{33} \mathrm{~J}$. Delorme, Gymnasion. Étude sur les monuments consacrés à l'education en Gréce des origines à l'Empire romain (Paris 1960) 444 y 445; M. Gally, "Pilgrimage as Elite Habitus. Educated Pilgrims in Sacred Landscape During the Second Sophistic", J. Elsner, I. Rutherford (eds.), Pilgrimage in Graeco-Roman \& Early Christian Antiquity. Seeing the Gods (Oxford-New York 2005) 269. 
A tenor de esa caracterización de los Asclepeia como auténticos complejos del saber, de escuelas a gran escala con una fuerza de atracción religiosa, médica y cultural que trascendía la influencia regional, recibieron la consiguiente admiración y atención paralela del poder romano y de las aristocracias municipales. El siglo II d.C. registra una evidente tendencia a restaurar y a reedificar los santuarios notorios del mundo griego (en ellos se multiplican los gimnasios, odeones, teatros y baños), si bien otras operaciones constructivas se atestiguan asimismo en fechas anteriores: de la exigua actividad edilicia del primer siglo del Imperio en la Atenas post-augustea, sólo el Asclepieion cosechó obras de mantenimiento $^{34}$. En Epidauro, la intervención del emperador Adriano no estribó en una monumentalización arquitectónica, sino en una reordenación de su sistema de datación, una regulación de los cargos sacerdotales y un refundación de los juegos celebrados durante las festividades de Asclepio ${ }^{35}$. La ambiciosa renovación del santuario de Pérgamo, financiada por L. Cuspio Pactumeyo Rufino y otros evergetas con espectaculares resultados -se intuye que a raíz de las visitas efectuadas por Adriano a la ciudad eólida en el 123 y el 128 d.C.-, lo elevó a la categoría de maravilla del mundo, recordada aún por los historiadores bizantinos en el siglo $\mathrm{XI}^{36}$. El nuevo complejo cultual mantuvo su antigua ubicación, pero al plano original se le sumaron una serie de edificios de arquitectura helenístico-romana (biblioteca, teatro, propileos, templos, gimnasio, un criptopórtico brindado a los incubantes, etc. ${ }^{37}$ ) que proveían a los usuarios del conjunto sacro de una amplitud de espacios donde desplegar una variedad de prácticas, entre las que las académicas no eran, precisamente, las menos atendidas: competiciones y exhibiciones musicales, literarias y atléticas se ofrecían en el gimnasio y en el teatro, en tanto que la biblioteca custodiaba textos de todos los géneros, aunque se ha especulado acerca de la preeminencia de los volúmenes pertinentes a la medicina ${ }^{38}$. Independientemente a la mayor o menor variedad temática, en academias templares donde se impartía esta ciencia, y al alcance de sus libros, es donde se forjó el aprendizaje de personajes como Galeno, autor de tratados de medicina que influenciarían en la medicina occidental hasta la época Moderna. Sin duda los pacientes del templo disfrutaban de todos estos servicios orientados al ocio, pero la sociedad erudita que frecuentaba estos asclepieia extraería de estos centros

${ }^{34}$ J. M. Camp, The Archaeology of Athens (New Haven 2004) 193.

${ }^{35}$ M. Melfi, I santuari di Asclepio in Grecia. I (Roma 2007) 83-86.

${ }^{36}$ A.-V. Pont, Orner la cité. Enjeux culturels et politiques du paysage urbain dans l'Asie gréco-romaine (Bordeaux 2010) 57 y 58.

${ }^{37}$ A. Petsalis-Diomidis, "The Body in Space: Visual Dynamics in Graeco-Roman Healing Pilgrimage", J. Elsner, I. Rutherford (eds.), Pilgrimage in Graeco-Roman \& Early Christian Antiquity. Seeing the Gods (Oxford-New York 2005) 188 y ss. Acerca de las transformaciones introducidas por Adriano en el Asclepieion, Ch. Habicht, Die Inschriften des Asklepieions (Berlin 1969) 9 y ss.

${ }^{38}$ A. Petsalis-Diomidis, "Truly Beyond Wonders". Aelius Aristides and the Cult of Asklepios (Oxford-New York 2010) 170 y 171; F. F. Brenk, "School and Literature. The Gymnasia at Athens in the First Century A.D.”, J. A. Fernández, F. Pordomingo, A. Stramaglia (eds.), Escuela y Literatura en Grecia Antigua (Cassino 2007) 341. 
culturales los verdaderos frutos para el intelecto. Los análisis epigráficos llevados a cabo por Milena Melfi y Bernadette Puech, en efecto, ponen de relieve cómo Asclepio rivalizaba con su padre Apolo por el patronazgo de las Letras, en palabras de la segunda: las inscripciones del periodo antonino atestiguan a numerosos filósofos, retóricos y poetas, en ocasiones enteras dinastías familiares ligadas al santuario, al sacerdocio o al culto de la divinidad sanadora, en Pérgamo, Epidauro, Eleusis o Atenas ${ }^{39}$. Se trata de dedicaciones de hermas y de estatuas, o de monumentos honorarios, a esta categoría de personajes, erigidos por ellos mismos, por sus allegados o alumnos recordando sus mercedes evergéticas, con la aprobación de la boulé, las cuales nos acercan a los grupos ciudadanos de la élite política, a aquéllos que desempeñaban los cargos municipales, a los instruidos dentro de los códigos morales y culturales de la paideia. Melfi ahonda en las figuras de Sexto Julio Mayor Antonino Pitodoro o de Tito Flavio Xenión, exponentes de la nobleza intelectual de Nisa y de Gortina respectivamente. Aquél, dadivoso benefactor del santuario de Epidauro (sufragó nada menos que los templos de Higía, de Asclepio y Apolo egipcios, de la hospedería, de una stoa, de una cisterna cubierta, etc.), mientras que el segundo levantó la imagen de culto del recinto de Lebena $(\mathrm{Creta})^{40}$. De Tito Estatilio Lamprias, quien compaginaba el sacerdocio de Asclepio en Epidauro con las tareas de gimnasarca en el "Liceo", tareas cívicas que le valieron la erección de sendos retratos en el santuario. $\mathrm{O}$ en las de los filósofos y oradores atenienses implicados en la recuperación de los ceremoniales, las procesiones y los ritos mistéricos de Asclepio, protagonistas de las recitaciones de himnos y poemas de contenido filosófico y religioso en honor del Esculapio romano en el teatro de Dioniso ${ }^{41}$. Por supuesto no falta la figura de $\mathrm{He}-$ rodes Ático, cuya munificencia para con la urbe ateniense se perpetuaba en una serie de esculturas. De la devoción que sintieron por él sus alumnos, así como del profundo respeto mostrado a su linaje, se conserva el resto epigráfico de una pareja de imágenes marmóreas dedicadas a su hija Marcia Claudia Atenaide, fallecida a los doce años de edad, igualmente recuperadas del Asclepieion ${ }^{42}$.

Lógicamente se les reservaba a estos individuos de refinada sabiduría, de inclinaciones filosóficas, retóricos y docentes de la ciudad, el cometido de procurar el renacimiento de los grandes santuarios griegos de Asclepio: exponentes de la Segunda Sofística, durante la cual la dimensión intelectual y educativa constituía una pieza más en el puzle de la reputación social, de la ascendencia sobre la

${ }^{39}$ B. Puech, Orateurs et sophistes grecs dans les inscripctions d'époque impériale (Paris 2002) 22 y 23.

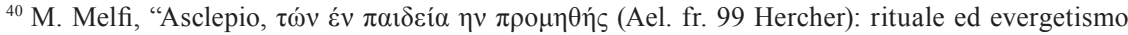
negli Asklepeia del II sec. d.C.”, O. D. Cordovana, M. Galli (eds.), Arte e memoria culturale nell'età della Seconda Sofistica (Catania 2007) 245-252. Igualmente los autores antiguos muestran este evergetismo por parte de los sectores eruditos de la sociedad: Filóstrato cita la donación de una fuente de aceite con la cubierta dorada al gimnasio del Asclepieion de Esmirna, realizada por Heraclides de Licia. Philostr. VS. 2.26, 613 .

${ }^{41}$ Ibid. 242 y ss; Ibid. I santuari..., op. cit. (2007) 388 ss.

${ }^{42}$ B. Puech, op. cit. 484-485, núms. 275-276. 
colectividad, enfocaron su obra cívica en el dios protector de la paideia. Asociado a este concepto, no podemos dejar de lado la popularización en el Oriente romano, por completo anómalo en las provincias occidentales, de la fundación de bibliotecas por iniciativa de ese sector privado nobiliario. Las beneficiarias no fueron únicamente las poblaciones con Asclepieia, si bien, los hallazgos epigráficos demuestran que en los tres santuarios de referencia panhelénica para quienes confiaban en las propiedades curativas del dios sí se emplazaron, quizá con objeto de cubrir la carencia de una biblioteca pública ${ }^{43}$. Flavia Melitene, pudiente esposa y madre de prítanes de la localidad pergamena, construyó en su Asclepeium una biblioteca presidida por una talla de Adriano divinizado (¿desencadenaría la visita del emperador en el año 123 la instauración de la biblioteca?), cuya imagen simbolizaba la protección imperial a esta clase de establecimientos ${ }^{44}$. En Epidauro, la institución del edificio, ofrecido a Apolo Melatas y a Asclepio por un evergeta de edad antonina, de nombre Rufo, se llevó a cabo acompañado de unos suntuosos juegos ${ }^{45}$. Una inscripción certifica que el médico personal de Claudio, Gayo Esterninio Jenofonte, titular de los sacerdocios de Asclepio, de Higía y del culto imperial, legó sus volúmenes al recinto sagrado de Cos -las estancias que ocuparía la biblioteca se han identificado arqueológicamente-, los cuales no habrían de limitarse en exclusiva a temas médicos, dada la multiplicidad de intereses de estos especialistas; su empleo bien podría haberse orientado hacia la enseñanza dentro del santuario, sea en la escuela de medicina que en las de filosofía, o haber distraído de sus cuitas a los pacientes que aguardaban los mensajes divinos entre sus muros ${ }^{46}$.

Otras construcciones cultuales, aparte de los Asclepieia, desempeñaron hasta bien entrada la Tardoantigüedad funciones investigadoras y pedagógicas, sustentadas en las cada vez más frecuentes colecciones de libros que se depositaban en ellas. Alrededor del año 381 d.C. en que Teodosio I procedió a la clausura de los templos paganos, y les privó de sus derechos, propiedades y tierras, Libanio se afligía en sus declamaciones de que la medida imperial acarrease la destrucción de esa riqueza bibliográfica, con obras históricas, de filosofía y de arte que custodiaban ${ }^{47}$.

${ }^{43}$ Además de las bibliotecas ligadas a estos santuarios, cabe destacar la fundación en el siglo II d.C. de la biblioteca de Panteno en Atenas (en torno al año 100 d.C.), de Celso en Éfeso (113 d.C.) o de Flavio Severiano Neón en Sagalassos (120 d.C.). A. Petsalis-Diomidis, op. cit (2010) 216.

${ }^{44}$ Por ejemplo, la biblioteca de Prusa, financiada por Dion, contaba con una escultura del emperador Trajano. F. Pesando, Libri e biblioteche (Roma 1994) 63 y 64. Acerca de la escultura dedicada por Flavia Melitene, así como sobre esta noble pergamena (y no una sacerdotisa ateniense, como ha sido demostrado), Ch. Habicht, op. cit. 84-85; M. Le Glay, "Hadrien et l'Asklépieion de Pergame", BCH 100 (1976) 350 y 351.

${ }^{45} \mathrm{~K}$. Staikos, The History of the Library in Western Civilization. From Cicero to Hadrian. The Roman World from the Beginnings of Latin Literature to the Monumental and Privates Libraries of the Empire (Kotinos 2005) 276 y 277.

${ }^{46}$ R. Nicolai, "Le biblioteche degli asclepieia", Nuovi Annali della Scuola Speciale per Archivisti e Bibliotecari II (1988) 33-37.

${ }^{47}$ R. Sanz Serrano, "The Seclusion of the Orator and the Decline of Hellenistic Paideia in the Christian Empire”, D. Hernández de la Fuente (ed.), New Perspectives on Late Antiquity (Cambridge 2011) 61. 
Decididos a convertir la capital egipcia en el referente científico del Mediterráneo helenístico, la Alejandría romana había recibido la preciosa herencia cultural del reino de los Ptolomeos, representada en el Mouseion -al que en breve volveré-, la Biblioteca Real y el Serapeum. En época de Aureliano, la segunda de las instituciones desapareció y el museo padeció un grave deterioro (con mayor precisión, a causa de su campaña contra la reina Zenobia del 272 d.C., cuyo ejército había invadido Egipto dos años antes ${ }^{48}$ ), granjeando a la hasta ahora "biblioteca filial" la preeminencia en la ciudad, aunque para entonces buena parte de los fondos librescos de la Biblioteca Real se habían trasladado al Caesareum y al templo de Claudio $^{49}$ (fig. 2). Guglielmo Cavallo intuye para el Alto Imperio un acceso a la biblioteca del Serapeum muy restringido a un círculo de sabios protegidos por el Estado, como ya sucediera durante los siglos del Helenismo que la vieron nacer ${ }^{50}$. El panorama debía de resultar harto distinto en el siglo IV d.C., cuando el filósofo neoplatónico Antonino, hijo a su vez de los profesores de filosofía Eustacio de Capadocia y de Sosípatra de Éfeso (ésta mantenía una escuela en su casa), daba sus clases a una multitud de jóvenes "hambrientos de filosofía" en el templo de Serapis, quienes simultáneamente ejercían de sacerdotes de la divinidad greco-egipcia ${ }^{51}$; el pío maestro incluso habría profetizado que a su muerte el complejo sería destruido, vaticinio que los tumultos encabezados por el patriarca Teófilo en el 391 d.C. propiciaron que se cumpliera. A cualquiera con voluntad de estudiar se le facilitaban los libros, escribe Aftonio de Antioquía, así que por entonces constituiría un animado liceo de la juventud deseosa de perpetuar el saber iluminado por el paganismo, reflejado en los volúmenes de su biblioteca, alabada por Amiano Marcelino (c. 335-400 d.C.), al igual que sus atrios, sus vastos pórticos, sus obras de arte y sus esculturas, todo ello considerado casi tan fastuoso como el Capitolio de Roma $^{52}$. Del valor de su patrimonio entre el sector erudito alejandrino es buen testimonio la colaboración de filósofos (como Olimpo el neoplatónico), poetas (Paladas y Claudiano) y profesores (Amonio y Heladio) en la defensa del monumento en el año $391^{53}$.

${ }^{48}$ P. Veyne, L'Impero greco-romano. Le radici del mondo globale (Bergamo 2009) 258-261.

${ }^{49}$ E. Watts, City and School in Late Antique Athens and Alexandria (Berkeley-Los Ángeles-London 2006) 149 y 150. Desde el siglo I a.C. el Caesareum tenía adosada una biblioteca grecolatina que pretendía rivalizar con las del Serapeum y con la Biblioteca Real. También conocido como el Sebasteum, el templo dedicado por Cleopatra a Marco Antonio en las cercanías del puerto del este fue convertido por Augusto en un centro consagrado a la divinidad de Julio César y al dominio de su dinastía sobre la ciudad. Es el único monumento descrito por Filón el Judío. K, Staikos, op. cit. 138-139; D. I. Sly, Philo’s Alexandria (London-New York 1996) 40.

${ }^{50}$ G. Cavallo, "Ambizioni universali e isolamento di una cultura", S. Settis (ed.), I Greci. Storia, Cultura, Arte, Società. 2. Una Storia Greca III. Transformazioni (Torino 1998) 237.

${ }^{51}$ Eun. VS. 6.

${ }^{52}$ G. Cavallo, op. cit. 247; D. Sola Antequera, M. Álvarez Sosa, "Alexandria ad Aegyptum. Memoria fílmica e iconos de una ciudad suspendida en la Historia”, Revista Latente 9 (2011) 23 y 24.

${ }^{53}$ F. J. Fernández Abad, "El Serapeo o Serapeum: Templo, Biblioteca y Centro de Investigaciones Científicas”, Revista General de Información y Documentación 18 (2008) 169. 
Entre el siglo I a.C. y el siglo V d.C., la capital soñada por Alejandro Magno en el Delta del Nilo se describe como una ciudad eminentemente estudiantil. Estrabón alude al continuado trasiego de alumnos extranjeros que desembarcaban allí y a la partida de muchos egipcios para formarse en otros destinos ${ }^{54}$. A mediados del siglo IV, la Expositio totius mundi et gentium retrata una Alejandría en la que se daba cabida a médicos y a filósofos de todas las escuelas y doctrinas, con enseñanzas de una alta especialización ${ }^{55}$, y a comienzos del V d.C. Sinesio de Cirene contrastaba la fecundidad del Egipto de Hipatia con la penuria que atravesaba el saber en Atenas $^{56}$. El gimnasio helenístico de la urbe había ido perdiendo sus funciones didácticas y atléticas ya cuando tanto le impresionó a Estrabón hacia el 24-23 a.C., y en el periodo Severiano, en sus ambientes y palestra se desarrollaban labores judiciales, administrativas e incluso reuniones mundanas ${ }^{57}$. Aunque se tiene constancia de la fundación de otro gimnasio en el reinado de Septimio Severo, la respuesta a la enorme demanda educativa que se generaba hubo de conceder una relevancia sin igual al templo de las Musas -el Mouseion por excelencia en toda la cuenca mediterránea según declaraba la Expositio $^{58}$-, al menos hasta el último cuarto del siglo III d.C., importancia que recuperó parcialmente en el siglo V. Simultáneamente a la investigación científica y a las actividades literarias bajo el auspicio de las Musas, se le ha reconocido al Mouseion una importante dimensión docente, modelado en la organización e ideario de la Academia y de las escuelas filosóficas atenienses. Fraser resalta la "secularización" de la institución y su viraje hacia cometidos formativos (tal vez en materias filosóficas, científicas y literarias) precisamente en época romana, misión compartida por el resto de museos debido a la influencia alejandrina, como en el caso del de Éfeso ${ }^{59}$. A pesar de la falta de pruebas arqueológicas, se le supondría la presencia de salas de conferencias, auditoria y exedras que facilitasen las lecciones y el intercambio de conocimientos $^{60}$. Suetonio aporta la pista de que el emperador Claudio amplió el antiguo Mouseion con otro nuevo que llevaba su nombre, en cuyos auditorios se leyeran

${ }^{54}$ Str. 14.3.13.

${ }^{55}$ Expositio totius mundi 34.15-25; 37.5-10.

${ }^{56}$ Synes. Ep. 136.15.

${ }^{57}$ F. Burkhalter, "Le Gymnase d'Alexandrie: centre administratif de la province romaine d'Égypte", BCH 116.1 (1992) 351, 367 y 368. Otras construcciones relacionadas con la cultura y la educación podrían haber sufrido procesos similares. Por ejemplo, se ha estimado que la Biblioteca de Adriano de Atenas (igualmente considerada un Panteón o un Foro imperial) podría haber sido la sede administrativa de la ciudad tardíamente, en los siglos III y IV d.C A. Karivieri, "The So-Called Library of Hadrian and the Tetraconch Church in Athens”, P. Castrén (ed.), Post-Herulian Athens (Helsinki 1994) 103. La dimensión educativa de los gimnasios griegos en época romana y su multifuncionalidad se discutirá en un tercer artículo concerniente a estos centros del saber.

${ }^{58}$ Expositio totius mundi 35.10.

${ }^{59}$ P. M. Fraser, Ptolemaic Alexandria. I. Text (Oxford 1972) 313-315.

${ }^{60}$ En el sentido de una exedra entendido por Vitrubio, de una estructura espaciosa diseñada para que filósofos y orados mantuvieran sus discusiones cómodamente sentados, modelo de los efebeos de los gimnasios. Ch. V. Daremberg, E. Saglio, Dictionnaire des antiquités grecques et romaines d'après les textes et les monuments II, 1 (Paris 1877-1919) 881; E. Watts, op. cit. 146-147. 


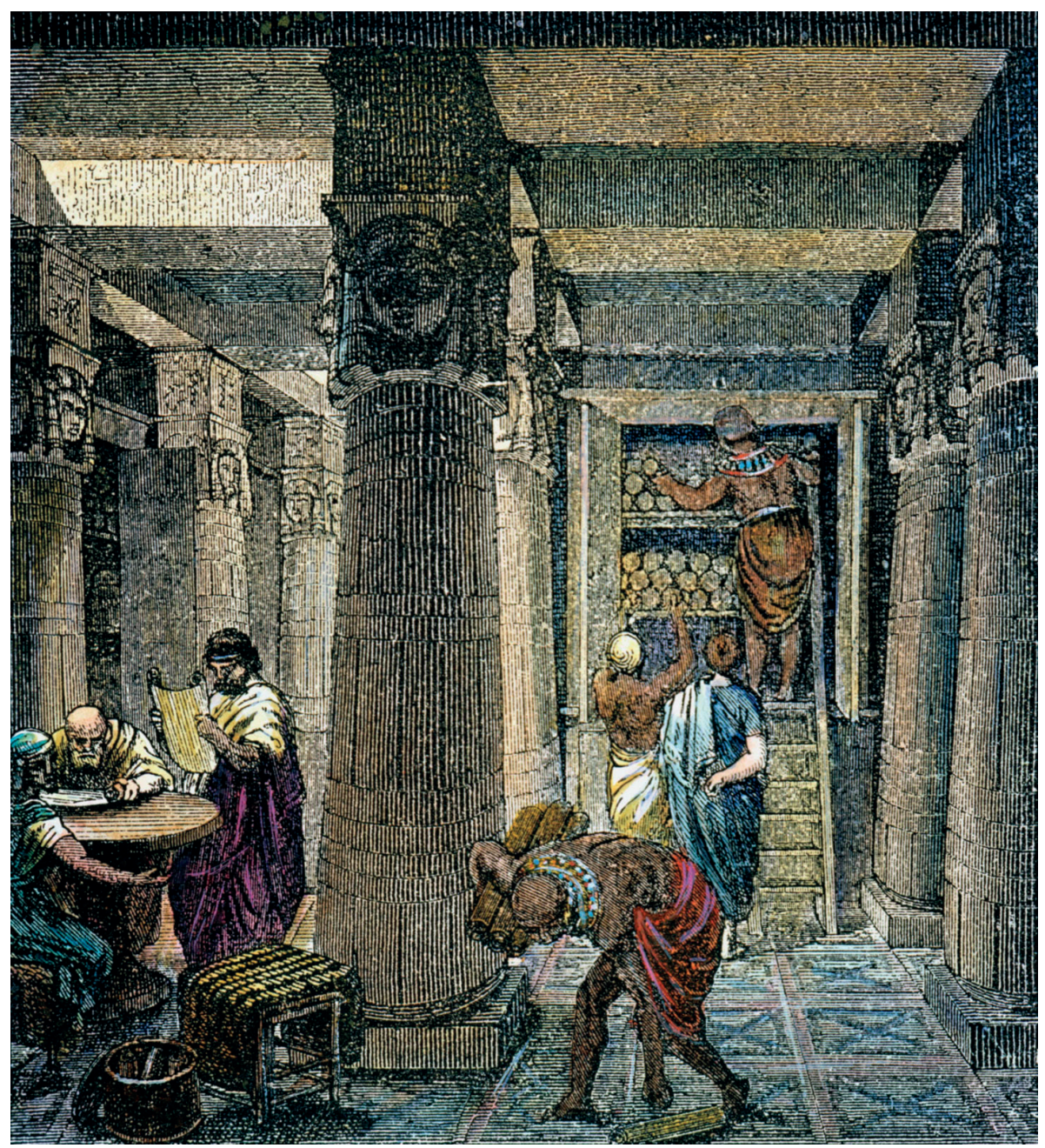

Figura 2. Grabado de la Biblioteca Real de Alejandría, s. XIX. Nueva York, The Granger Collection

todos los años, y de principio a fin, los veinte libros de historia etrusca, y los ocho de historia cartaginesa, compuestos por él mismo ${ }^{61}$. Dichas salas de recitación pública existían con precedencia a la remodelación de Claudio, pero quizá la meta de ésta se dirigía a acrecentar las áreas dedicadas a la educación. Durante su existencia, del mismo modo que realizaron los monarcas helenísticos, los emperadores contemplaron el templo de las Musas como una empresa dependiente del Estado, nombraron directamente a sus miembros, les costearon su estipendio y decretaron exenciones fiscales a su favor. En casos como los de los sofistas Polemón de

\footnotetext{
${ }^{61}$ Suet. Claud. 42.
} 
Laodicea y de Dionisio de Mileto entrevemos el crédito vinculado a la manutención honorífica a expensas publicas en calidad de componentes del Museo, y quiénes eran los agraciados: aquél, un retórico procedente del seno de una estirpe consular, favorecido por ciudades y emperadores, y presidente vitalicio de los juegos instaurados por Adriano en Esmirna. El segundo, elevado al orden ecuestre durante la administración adrianea y procurador de distintas provincias ${ }^{62}$. La merced, como decía, era totalmente de carácter honorífico, pues ambos oradores ni siquiera residían en Alejandría, pero no resulta difícil intuir dádivas y subvenciones idénticas para los integrantes institucionales de facto. En el Mouseion se disponía una habitación para las pitanzas colectivas, circunstancia que despierta la incertidumbre de si residían allí de forma colegiada ${ }^{63}$.

Por supuesto, los museos constituían realidades habituales en las urbes grecorromanas ${ }^{64}$. En opinión de Bernadette Puech, sus elementos consistían en un altar de las Musas, una biblioteca, un pórtico, una exedra y algunos árboles, articulados en cualquier lugar, público o privado, encauzado hacia las actividades intelectuales ${ }^{65}$. La laxitud de algunas de estas características dificulta la identificación arquitectónica de estas estructuras, así como la presencia o la ausencia de la iconografía de las musas tampoco tiene por qué arrojar datos concluyentes y puede deberse a contingencias meramente históricas y arqueológicas. Su adscripción inmediata a una arquitectura educativa resulta aún más compleja. En Side, un importante núcleo urbano de la provincia de Licia-Panfilia, el furtivo Edificio $\mathrm{M}$ fechado en edad antonina, se ha asimilado a una biblioteca (por su reproducción de la planta de la biblioteca de Adriano en Atenas), a un ágora y a un gimnasio-museo. Se trata de una edificación consistente en una amplia plaza porticada a la que se asoman tres ambientes, de los cuales, el central se hallaba decorado con dos órdenes de nichos enclavados en una monumental arquitectura muraria de mármoles policromos. Estatuas de divinidades y personajes mitológicos (Hermes, Higía, Asclepio, Ares, Marsias, Némesis, Demetra, Heracles...) se combinaban en las treinta y cuatro aediculae con figuras de atletas, imágenes de culto imperial y quizá el retrato del evergeta del conjunto ${ }^{66}$. En su asignación a un ágora civil o segunda ágora de Side, sendos espacios laterales se han referido como una basílica y una biblioteca o archivo, mientras que Pierre Gros, que resalta las semejanzas formales del complejo a una palestra, las individualiza

\footnotetext{
${ }^{62}$ Philostr. VS. 1.22.524; 1.25.530-532.

${ }^{63}$ P. M. Fraser, op. cit. 315.

${ }^{64}$ En Roma, Marco Fulvio Nobilior fundó un templo dedicado a Hércules y a las Musas, donde alojó el botín conseguido tras el saqueo de la antigua capital de Pirro, y a comienzos del siglo II a.C. base de la Liga Etólica. Su protegido, el poeta Quinto Ennio, organizó el recinto a modo de Mouseion, en imitación del alejandrino, como centro de enseñanza y lo dotó de una biblioteca. K, Staikos, op. cit. 32.

${ }^{65}$ B. Puech, op. cit. 84; A.-V. Pont, op. cit. 106.

${ }^{66}$ F. Slavazzi, "Uso dei modelli e recupero del passato nei programmi scultorei ufficiali di età antonina in Asia Minore”, O. D. Cordovana, M. Galli (eds.), Arte e memoria culturale nell'età della Seconda Sofistica (Catania 2007) 131 y ss.
} 
como posibles bibliotecas o auditoria, dotadas ambas de sus propios edículos ${ }^{67}$. Fabrizio Slavazzi añade la posibilidad de vislumbrar en el Edificio $\mathrm{M}$ el gimnasio que las excavaciones todavía no han localizado en el yacimiento, y en cuyo interior quedaría integrado el Mouseion mencionado en una inscripción ${ }^{68}$. La dificultad de tipificar la construcción de Side entronca con la existencia física en las ciudades de instituciones decantadas hacia la cultura, en las que se imbricaban las diligencias eruditas, la investigación científica y la pedagogía municipal, provistas de auditorios, bibliotecas, espacios de ejercicios físicos, y que en este caso ha dado pie a su interpretación como un gimnasio, una biblioteca $o$, parcialmente, un

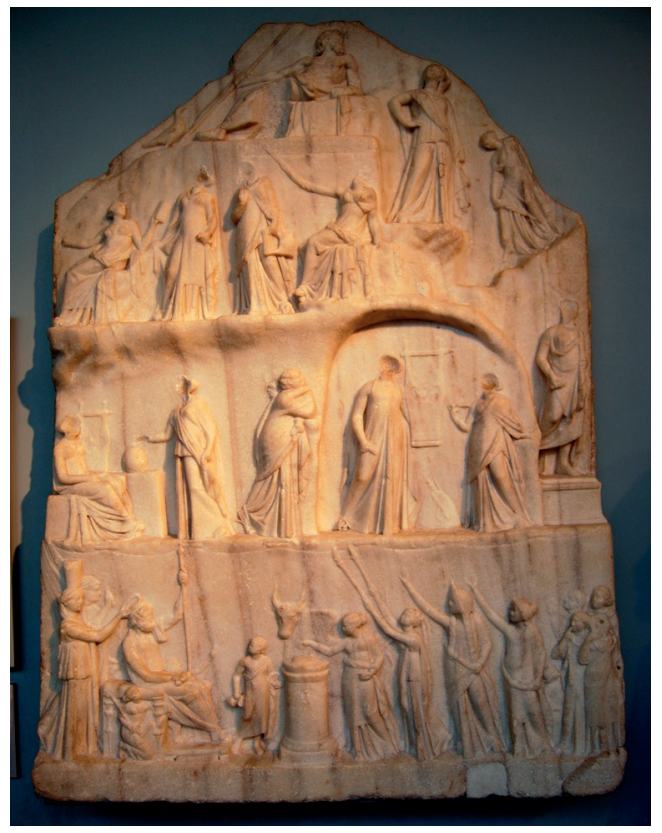

Figura 3. Apoteosis de Homero, s. III a.C. Londres, British Museum templo de las Musas. Lugares así se erigieron en Éfeso, Esmirna o Afrodisias, y uno de los máximos honores con que se podía glorificar a los poetas radicaba en colocar sus estatuas broncíneas en ellos, así como en los gimnasios. Como arquetipo más institucional que tipológico, es incluso lícito cuestionarse entonces si los museos, en su origen meras capillas o altares en torno a los que se desplegaban los certámenes poéticos y literarios, imprimieron sus características en los homereia. Estrabón citaba una biblioteca en relación con el Homereion de Esmirna, consistente en un santuario - con un xoanon de madera como imagen cultual- rodeado de un pórtico ${ }^{69}$ (fig. 3). Anne-Valérie Pont sugiere la probabilidad de que sea este establecimiento que el Museo formaran parte de un mismo complejo monumental ${ }^{70}$. En conexión con otra biblioteca, la del Serapeo de Menfis, una

${ }^{67}$ P. Gros, L'architecture romaine du début du III siècle av. J.-C. à la fin du Haut-Empire. I. Les monuments publics (Paris 1996) 370; E. Akurgal, Ancient Civilizations and Ruins of Turkey (Istanbul 2011) 340 y 341 .

${ }^{68}$ F. Slavazzi, op. cit. 131.

${ }^{69}$ Str. 14.37. Homero fue venerado como un héroe desde el Helenismo. Un relieve dedicado por Arquelao de Priene hacia el 150 a.C. lo muestra entronizado, con una iconografía cercana a la de Zeus, rodeado de las Musas. P. Zanker, La maschera di Socrate. L'immagine dell'intellettuale nell'arte antica (Turín 1997) 159-162. El prototipo retratístico del Homero tipo Apolonio seguramente proceda de una imagen cultual existente en su santuario de Esmirna. S. F. Schröeder, Catálogo de la escultura clásica del Museo del Prado. I. Retratos (Madrid 1993) 84 y 85, núms. 17-18.

${ }^{70}$ A.-V. Pont, op. cit. 107. 
estatua sedente de Homero presidía una decena de figuras de poetas y filósofos ordenados en semicírculo en una exedra, aunque a priori nada sugiere su culto alli $^{71}$ (figs. 4-5). Un cuadro iconográfico similar se ofrecía en el templo homérico de Alejandría, donde sí se veneraba al poeta épico, aquí rodeado por un hemiciclo de personificaciones de las ciudades que reivindicaban el ser su cuna, y donde supuestamente podrían haberse construido los consiguientes Homereia ${ }^{72}$. A diferencia que con los museos, salvo intuir ciertas labores de la esfera de las Letras y la celebración de competiciones líricas o de supuestas efemérides homéricas, poco más se puede afirmar. Que en el propio monumento o en su inmediata vecindad topográfica aparezca una biblioteca, distintivo compartido con los santuarios de las Musas, no haría incoherente pensar en alguna modalidad instructiva.

A partir del cambio de Era, los auditoria, entendidos como los locales donde filósofos y retóricos tenían sus lecciones y pronunciaban sus conferencias o efectuaban sus lecturas, se consolidan como un componente más de la arquitectura de la biblioteca ${ }^{73}$. En torno al 100 d.C., la biblioteca fundada por Tito Flavio Panteno no lejos del ágora ateniense, contaba con sendas exedras en las que se sostenían dichos actos públicos. En la misma ciudad, el lado este de la de Adriano, presidido por la sala en la que se conservaban los libros, se remataba con dos auditorios cuadrangulares de dieciséis metros de lado, dotados de una plataforma consignada a los oradores y una veintena de gradas ligeramente curvilíneas para los espectadores ${ }^{74}$. La edificación absidial adyacente a la biblioteca de Celso en Éfeso (117 d.C.) se ha reconocido como el "auditorion" mencionado en un epígrafe evergético ${ }^{75}$. Sin embargo, la helenización del término latino, en vez de emplear una palabra griega, ha movido a apreciar que tradujese una realidad judicial o administrativa romana, una suerte de archivo legal relacionado con el gobierno de la provincia de Asia y con su procónsul ${ }^{76}$. Barbara Burrell demuestra, por el contrario, que allí profesores y disertantes, "las estrellas de la Segunda Sofística", desplegaban sus habilidades y enseñaban ${ }^{77}$. En la plaza delantera se alzaba además la tumba y la estatua honorífica de un célebre retórico y maestro que culminó su carrera en Éfeso, el ya señalado Dionisio de Mileto, sin duda un personaje que ejercía su profesión en el interior del auditorio.

${ }^{71}$ J.-P. Lauer, C. Picard, Les statues ptolémaïques du Sérapiéion de Memphis (Paris 1955); G. Cavallo, op. cit. 237.

${ }^{72}$ P. Zanker, op. cit. 161

${ }^{73}$ P. Gros, op. cit. 373.

${ }^{74}$ L. Casson, Libraries in the Ancient World (New Haven - London 2001) 113 y 114; F. Pesando, op. cit. 65 .

${ }^{75}$ En ella se anunciaba que la herencia legada por Julia Potentila había costeado la pavimentación de la superficie frente al auditorio y la biblioteca de Celso. J. Platthy, Sources on the Earliest Greek Libraries with the Testimonia (Amsterdam 1968) 157.

${ }^{76}$ V. M. Strocka, "The Celsus Library in Ephesus", Ancient Libraries in Anatolia. Libraries of Hattusha, Pergamon, Ephesus, Nysa (Ankara 2003) 43.

${ }^{77}$ B. Burrell, "Reading, Hearing, and Looking at Ephesos", W. A. Johnson, H. N. Parker (eds.), Ancient Literacies. The Culture of Reading in Greece and Rome (Oxford 2009) 85-89. 
ARQUEOLOGÍA DE LA PAIDEIA. LAS SEDES DE LA EDUCACIÓN SUPERIOR...

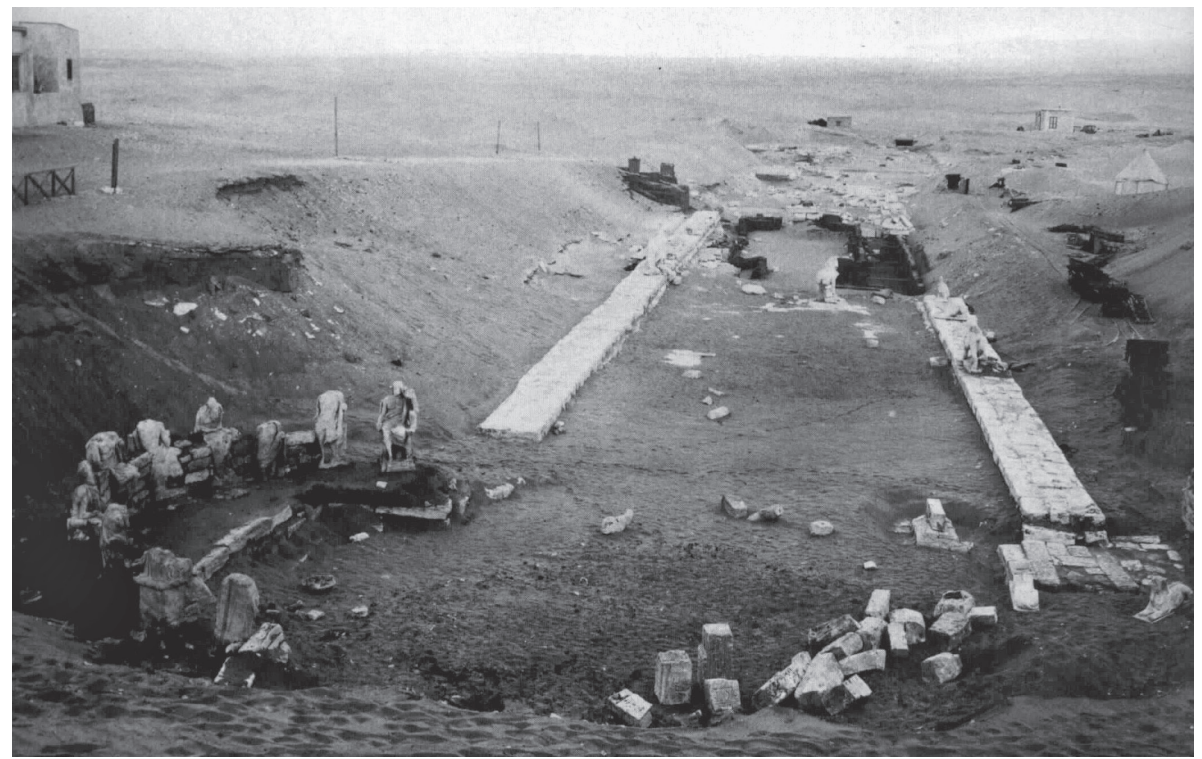

Figura 4. Hemiciclo de los Filósofos del Serapeum de Saqqara (Lauer y Picard 1955).

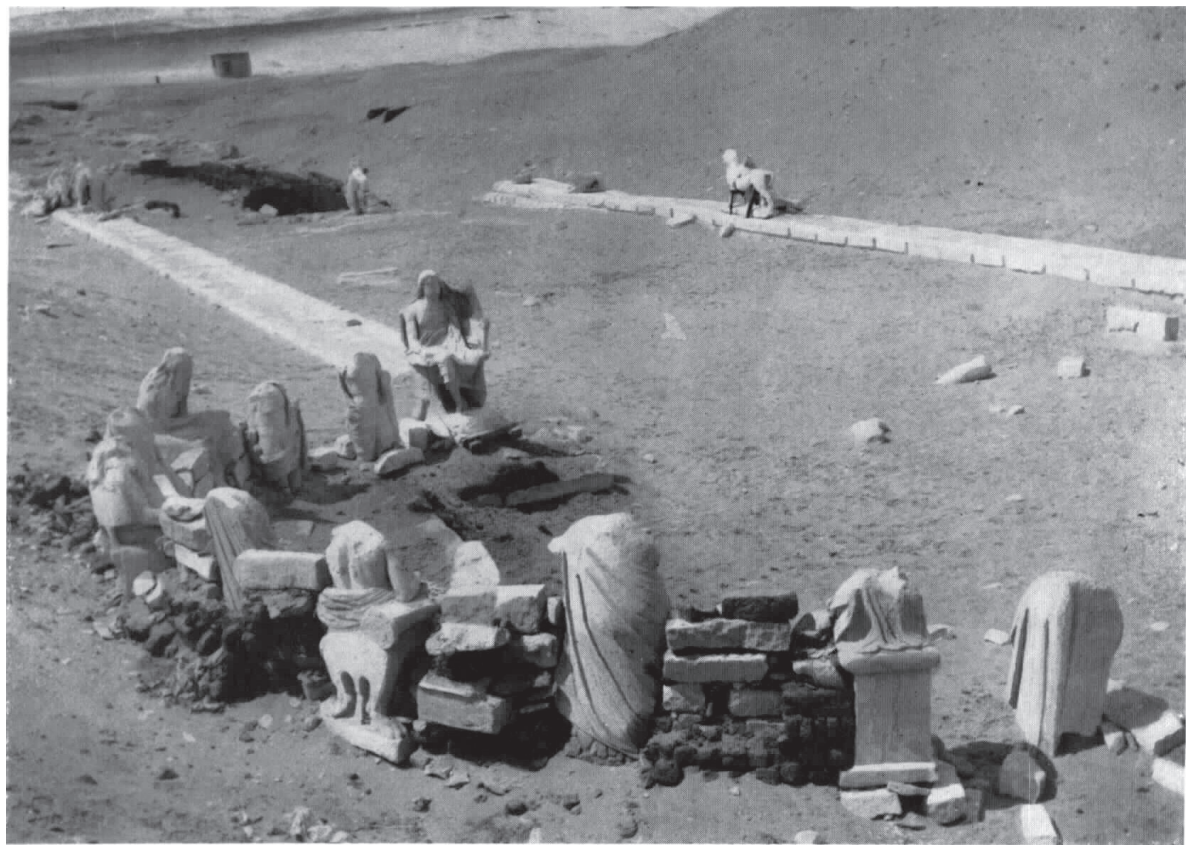

Figura 5. Hemiciclo de los Filósofos del Serapeum de Saqqara (Lauer y Picard 1955). 
Al replicar el modelo y el funcionamiento del Mouseion de Alejandría, los museos grecorromanos, pero asimismo otras entidades con actividades pedagógicas autorizadas por el municipio y por el emperador, crearían sus cuerpos privativos de docentes y de personalidades doctas. Se reconocía así la trascendencia de la cultura en el seno de la comunidad, aunque admitiendo la dependencia de ese conocimiento a los valores económicos, políticos, sociales e intelectuales impuestos por el poder imperial ${ }^{78}$. Al instaurarse en Atenas las cátedras imperiales de retórica y de filosofía entre el 173 y el 176 d.C. (con un profesor en la primera disciplina, y acaso hasta ocho en la segunda, dos por cada escuela), Marco Aurelio reservó la potestad de escoger al sofista titular del thronos de la elocuencia a los emperadores, en tanto que al político y orador Herodes Ático le concedió la libertad de decidir sobre los restantes ${ }^{79}$. Fallecido Herodes, el consejo ciudadano cubrió el proceso de selección, pero la máxima autoridad de Roma siempre gozó de la prerrogativa de interferir en la elección, de ratificar a los candidatos o en realidad de imponer al titular; si no en persona, sí a través del procónsul de Acaya, erigido en curator del organismo educativo imperial ${ }^{80}$. Luciano satirizó la pugna que surgía en la ciudad cuando, fallecido uno de los maestros, se convocaba un concurso entre los sofistas con objeto de ocupar la vacante ${ }^{81}$. El asunto no era para menos, porque, aparte de los 10.000 dracmas anuales de estipendio que recibía el escogido, y que apuntaba el escritor griego, los emperadores le otorgaban generosas dádivas y dispensas: Adriano de Tiro, discípulo de Herodes, no sólo recibió de Marco Aurelio oro y plata, caballos y esclavos, sino su manutención a expensas públicas, un sitial preferencial en los espectáculos, una completa exención fiscal y además obtuvo dignidades sacerdotales ${ }^{82}$; consciente de la solemnidad de su cargo, acudía a impartir sus clases en carruaje, enjoyado y ataviado con boato. No creo que todos los sofistas nominados adquirieran tales parabienes, sino aquéllos más próximos al emperador de turno (por ejemplo, Pólux de Náucratis fue profesor de Cómodo), que lo hubieran abordado en embajadas o cuya reputación hubiera tenido resonancias hasta en Roma, pero las franquicias tributarias o la concesión del sustento a cargo de la municipalidad debieron de ser comunes. Así el emperador se aseguraba también de la fidelidad incondicional de ese grupo de sabios -los soberanos helenísticos habían recurrido antes a esa fórmula-, cuyo estatus e importancia social, aparte de su buena cuna

\footnotetext{
${ }^{78}$ Y. Lee Too, The Idea of the Library in the Ancient World (Oxford 2010) 225.

${ }^{79}$ Los puestos municipales se habían fundado previamente, ya que en el siglo I d.C. el platónico Amiano, maestro de matemáticas y de filosofía de Plutarco, coordinaba como estratego el funcionamiento del conjunto de las escuelas de Atenas. Durante el festival de las Musas, y apoyado por los pedagogos oficiales, relataba Plutarco que supervisó los exámenes de gramática, geometría, retórica y música de los estudiantes a punto de acceder a la efebía, pruebas que tuvieron lugar en el gimnasio conocido como el Diogeneion. Plu. Quaest. Conv. 9.1.

${ }^{80}$ J. W. H. Walden, op. cit. 138-139.

${ }^{81}$ Luc. Eun.

${ }^{82}$ Philostr. VS. 2.10.589. Igualmente léase M. di Branco, La città dei filosofi. Storia di Atene da Marco Aurelio a Giustiniano (Firenze 2006) 17.
} 
natural, se encadenaba a los intereses del Estado. Por otro lado, las cátedras se ocupaban durante un número indeterminado de años, seguramente de forma vitalicia: Teodoto, primero en desempeñar la de retórica, se mantuvo en ella dos años, pero Pólux de Náucratis y Pausanias de Cesarea trece y dieciséis respectivamente (del 180 al 193 d.C. aquél, y de ese año al 209 d.C. éste) ${ }^{83}$.

Con el paso del tiempo, nuevas cátedras oficiales se abrirían en Nicomedia, Cesarea, Nicea, Antioquía (en época de Libanio contaba al menos con tres profesores de retórica, uno de leyes y otro de latín), Constantinopla, Beirut, y otras localidades de las provincias orientales, donde las regulaciones del Imperio se harían cada vez más presentes, en contraste, quizá, con los centros menores, en los cuales su injerencia se diluiría en beneficio de una actuación más acusada de los poderes locales. Resulta evidente que en materia de educación la Administración romana fue asumiendo ese papel predominante, cuyo reflejo se conserva en el Edicto de Precios Máximos de Diocleciano del 301, en el que se incluía a todas las categorías de los profesionales de la enseñanza, o en el Código Teodosiano. Promulgado en el 370 por los emperadores Valentiniano I y su hermano Valente, y por el Augusto Graciano el Joven, un decreto incluido en el Codex obligaba a los jóvenes que desearan cultivarse en Roma a portar consigo su certificado de nacimiento, documentación oficial que indicase su ciudad de proveniencia, junto al permiso de viajar, y cartas de recomendación, además de señalar los estudios que seguirían, cuya caducidad se estipulaba a los veinte años de edad, bajo pena de expulsión de la capital ${ }^{84}$. Si los salarios, las condiciones de enseñanza, las particularidades del profesorado y el comportamiento del alumnado se ajustaban paulatinamente a una normativización, algo similar hubo de suceder con las sedes orientadas al aprendizaje estatal, pero indudablemente se trata de un fenómeno tardío. A partir de un paso de Filóstrato se ha querido identificar el asiento de las lecciones de los retóricos y filósofos de nómina imperial de Atenas en el Odeón de Agripa ${ }^{85}$. Tras sufrir un catastrófico incendio a mediados del siglo II d.C., el monumento se había restaurado dando cabida a una menor afluencia de espectadores, lo cual espoleó a Herodes Ático a costear un nuevo odeón en torno al 160 d.C., aumentando la capacidad de asistencia a las lecturas, conferencias y certámenes ${ }^{86}$. Igualmente, se ha estimado que sería en el Ptolemaion donde se darían cita estos profesores, tal vez porque en época de Pausanias el gimnasio de Ptolomeo aún se manifestaba activo, y en el siglo I a.C. había constituido un interesante foco de atracción para Cicerón y otros alumnos romanos que se habían desplazado a la capital ática ${ }^{87}$. Podría ser más adecuado pensar que las enseñanzas se

${ }^{83}$ Ibid. 12-19.

${ }^{84}$ M. Joyal, I. McDougall, J. C. Yardley, op. cit. 250-251.

${ }^{85}$ Filóstrato refiere las conferencias de Herodes Ático y de Alejandro de Seleucia ante los alumnos de ambos en el Agripeion. Philostr. VS. 2.5.571. Véase M. di Branco, op. cit. 15-16.

${ }^{86}$ J. M. Camp, op. cit. 217-218.

${ }^{87}$ Paus. 1.17.2. Sobre el Ptolomaion, J. Delorme, op. cit. 146-147. 
continuaban desarrollando en la multitud de edificios apropiados al respecto, en los gimnasios, en los santuarios y templos, en los dos odeones, en el teatro, incluso en la Biblioteca de Adriano, sobre la cual se ha especulado que pudo ser la nueva Academia ateniense, en sustitución de la de Platón, arrasada durante la ocupación silana del 86 a.C. ${ }^{88}$. Ninguna fuente documenta para este momento que las cátedras municipales e imperiales gozaran de espacios privilegiados, aunque en la misma ciudad de Roma podría estar dándose entonces ese proceso de especialización conectado a un establecimiento determinado que no se descubre con claridad en Oriente, el Ateneo de Adriano. Pero a él volveré más adelante.

En el caso de Libanio, en cambio, sí constataba al principio del artículo como el templo de la Fortuna y el bouleuterion de Nicomedia, y el Museo de Antioquía, eran recintos privativos del profesorado dependiente de la ciudad a mediados del siglo IV. Pero será en Constantinopla donde las diferencias entre la didáctica pública y privada, y los espacios reservadas a aquélla, queden perfectamente pautados. Con la fundación del Auditorium Capitolii (a menudo traducido como "Universidad") en el 425 d.C., Teodosio II organizó la educación superior a nivel estatal, dependiente de un determinado cuerpo docente, con una sede fija. Así no se suprimía la formación privada, pero sí se ponía fin a la libertad de la pública, y desde entonces, los maestros asociados al programa imperial sólo serían retribuidos por sus arcas, impidiéndoseles desplegar su profesión en el ámbito particular, mientras que la bolsa de los pedagogos ajenos a este sistema se supeditaba a las compensaciones obtenidas de su alumnado ${ }^{89}$. A los tres oratores y diez grammatici de elocuencia romana, a los cinco sofistas y diez gramáticos de oratoria helena, a los dos profesores de derecho y al de filosofía, se les asignaron sus ambientes específicos en el auditorio imperial del Capitolio, con el propósito, decía el decreto, de que alumnos y profesores no se entremezclaran confusamente y de que el bullicio de lenguas y de discursos no distrajese la mente de los discípulos ${ }^{90}$. Entonces los eruditos de la capital de Oriente tenían asimismo a su disposición la nutrida biblioteca real, fundada a mitad del siglo IV por Constancio II y enriquecida con los volúmenes de la colección personal del emperador Juliano, la cual ardió, sin embargo, en el 476 d.C., siendo reconstruida quince años después ${ }^{11}$. Se ubicaba en la basílica del foro, que, al menos en la juventud del Apóstata, no sólo había albergado la corte judicial, o los templos de Cibeles y de la Fortuna, sino también la escuela donde el futuro emperador aprendía retórica con el sofista $\mathrm{He}$ cebolio y gramática con Nicocles de Lacedemonia ${ }^{92}$. No sabemos nada más de ese auditorium asociado a los templos de Júpiter, Juno y Minerva, así como al

${ }^{88}$ P. León Alonso, "Los espacios del saber y del pensamiento en el mundo griego", Boletín de la Real Academia Sevillana de Buenas Letras: Minervae Baeticae 36 (2008) 51-54.

${ }^{89} \mathrm{P}$. Lemerle, Le premier humanisme byzantin. Notes et remarques sur enseignement et culture a Byzance des origins au Xe siécle (Paris 1971) 63 y 64.

${ }^{90}$ J. W. H. Walden, op. cit. 148-149; M. Joyal, I. McDougall, J. C. Yardley, op. cit. 252-253.

${ }^{91}$ P. Lemerle, op. cit. 56-62, 65-66.

${ }^{92}$ Socr. Sch. HE. 3.1. S. Bassett, The Urban Image of Late Antique Constantinople (New York 2005) 24. 
culto imperial, todavía en uso a mediados del siglo $\mathrm{VI}^{93}$. Sí podemos añadir que, en esa evolución del control imperial sobre el mundo educativo, la fundación capitolina suponía un paso importante respecto a la o las escuelas de la basílica, y que a tenor del volumen de los especialistas del magisterio constantinopolitano, y de la agitada concentración estudiantil citada, nos enfrentamos verosímilmente a un complejo de auditorios de unas posibilidades y dimensiones nada desdeñables (si los treinta y un maestros disertaban contemporáneamente, tendríamos el número correspondiente de aulas). Aunque tampoco se posee información arqueológica o topográfica de los auditorios destinados al estudio de las leyes de Beirut, ni se conoce si eran estructuras independientes o formaban parte de otros edificios, como bibliotecas, basílicas o santuarios, acaso nos hallemos frente a una tipología cercana a la explicada en la antigua Bizancio ${ }^{94}$. De manera semejante a ésta, la ciudad fenicia gozaba de una agitada vida estudiantil que se aglutinaba en las materias de derecho y de latín. Zacarías Escolástico y Severo se desplazaron a ella en el 487 d.C. con la intención explícita de granjearse una profunda base jurídica para emprender la carrera civil (el primero sería abogado en Constantinopla), tras instruirse en gramática y retórica en Alejandría, y allí coincidieron con muchachos de Gaza, Cesarea, Afrodisias, Capadocia, Egipto, etc. ${ }^{95}$. La Expositio la define, en esencia, por ser la cantera de magistrados, abogados y juristas que se diseminaban por todas las provincias del Imperio, y destacaba las escuelas a las que acudían: Berytus era una "ciuitas ualde deliciosa et auditoria legum habens per quam omnia iudicia Romanorum stare uidentur" ${ }^{96}$. La introducción al Digesto del 533 d.C. confirmaría la primacía de la urbe, distinguida por Justiniano como la única capacitada para producir y copiar los textos legales que se difundían por los territorios imperiales ${ }^{97}$.

Las fuentes relatan algunos de los métodos de aprendizaje del derecho -los escolares asistían a las lecciones y después se las repetían entre ellos, o discutían los comentarios contenidos en los compendios legislativos-, pero cuáles eran las características formales precisas de esos auditorios se nos escapa. Sin embargo, desde la década de los ochenta del siglo pasado, y hasta comienzos del actual, la excavación de una serie de estructuras en Kôm el-Dikka (Alejandría) podría dar la clave definitiva de qué tipología edilicia acabaría por implantarse en la

${ }^{93}$ El Capitolio de Constantinopla se cree levantado por Constantino y consagrado a la Tríada Capitolina como un símbolo de la romanidad y de la herencia histórica recibida por la nueva capital. A pesar de su titularidad pagana, existen noticias de que de algún modo era un monumento cristianizado, ya que una cruz coronaba la parte superior, la cual fue derribada por una tempestad en el año 407. C. Mango, Le développement urbain de Constantinople (IVe-VII siècles) (Paris 1985) 30.

${ }^{94}$ Sobre los auditorios de Beirut, L. Jones Hall, Roman Berytus. Beirut in Late Antiquity (London 2004) 67.

95 J. Ma Blázquez, "La vida estudiantil en Beyruth y Alejandría a final del siglo V según la Vida de Severo de Zacarías Escolástico. Paganos y Cristianos (I)”, Gerión 16 (1998) 416 ss.

${ }^{96}$ Expositio totius mundi 25.

${ }^{97}$ L. Jones Hall, op. cit. 202. 
Tardoantigüedad como alternativa a gimnasios, santuarios, etc., y en convivencia con otros establecimientos cristianos al uso ${ }^{98}$. El distrito de Kôm el-Dikka sufrió una complicada evolución arqueológica: de un barrio residencial en los siglos II y III d.C., pasó a convertirse en un área tapizada con distintos espacios y monumentos públicos en los dos siglos siguientes, hasta que, tras el terremoto del año 535, su remodelación lo consolidó como el corazón de la vida social y educativa de la Alejandría bizantina ${ }^{99}$. A lo largo de los trabajos indicados se halló una sucesión de al menos veinte auditorios, asomados casi en su totalidad a un elegante pórtico columnado, de rasgos arquitectónicos similares (figs. 6-7): alineados en un eje norte-sur (salvo dos, orientados este-oeste), y de forma rectangular (de aproximadamente 9-11 x 5-5,5 metros), en su interior se disponían varas filas de bancos de piedra extendidos en tres de sus lados, curvados en hemiciclo; el extremo abierto contaba en su centro con un estrado sobre el que se situaría el asiento del profesor, su thronos, y desde un pequeño pedestal los alumnos declamarían ante los condiscípulos ${ }^{100}$ (fig. 8). La capacidad del complejo, en uso desde los momentos finales del siglo V, se estima de entre 500 y 600 estudiantes, y en él se cubrirían campos fundamentales del saber (aunque se ignora si los niveles de enseñanza desarrollados en él eran diversos) tales como la retórica, la jurisprudencia y la medicina, sin excluir la instrucción histórica, literaria o científica en general $^{101}$. Comparado tipológicamente con los bouleuteria, los efebeos y hasta con las exedras de ciertos Asclepieia ${ }^{102}$, se encuentra fuera de cuestionamiento la titularidad imperial o cívica de este conjunto de auditorios. La palabra "Universidad" surte inmediatamente al buscar una denominación adecuada para los ambientes de Kôm el-Dikka, y si bien se deben evitar paralelismos enturbiados desde nuestra perspectiva moderna, que allí tenía su sede algún tipo de escuela superior es casi innegable.

${ }^{98}$ Z. Kiss, "Les auditoria romains tardifs", Z. Kiss, G. Majcherek, H. Meyza, H. Rysiewski, B. Tkaczow (eds.), Alexandrie VII. Fouilles polnaises à Kôm el-Dikka (1986-1987) (Warszawa 2000) 9-33.

${ }^{99}$ C. Haas, "Kôm el-Dikka in context: the Auditoria and the History of Late Antique Alexandria", T. Derda, T. Markiewicz, E. Wipszycka (eds.), Alexandria Auditoria of Kôm el-Dikka and Late Antique Education (Warszawa 2007) 86 y 87.

${ }^{100}$ G. Majcherek, "The Late Roman Auditoria of Alexandria: an Archaeological overview", T. Derda, T. Markiewicz, E. Wipszycka (eds.), op. cit. 17, 38-39; C. Haas, op. cit. 87 ss. Próximo a los auditorios, un odeón o teatro de reducidas dimensiones, fechado en el siglo IV y con reestructuraciones hacia el 500, recibiría las conferencias de mayor relevancia, los espectáculos musicales, las recitaciones poéticas y las sesiones del consejo cívico. J. S. McKenzie, "The Place in Late Antique Alexandria Where alchemists and scholars sit (...) was like stairs", T. Derda, T. Markiewicz, E. Wipszycka (eds.), op. cit. $75-77$.

${ }^{101}$ En varios de los auditorios se han hallado piscinas excavadas en el suelo, cercanas a los umbrales, que se interpretan como receptores de la sangre y los desechos de los restos animales analizados durante las lecciones médicas. C. Haas, op. cit. 91.

${ }^{102}$ K. E. Welch, "Some architectural prototypes for the auditoria at Kôm el-Dikka and three Late Antique (fifth cent. AD.) comparanda from Aphrodisias in Caria”, T. Derda, T. Markiewicz, E. Wipszycka (eds.), op. cit. 117 ss. 


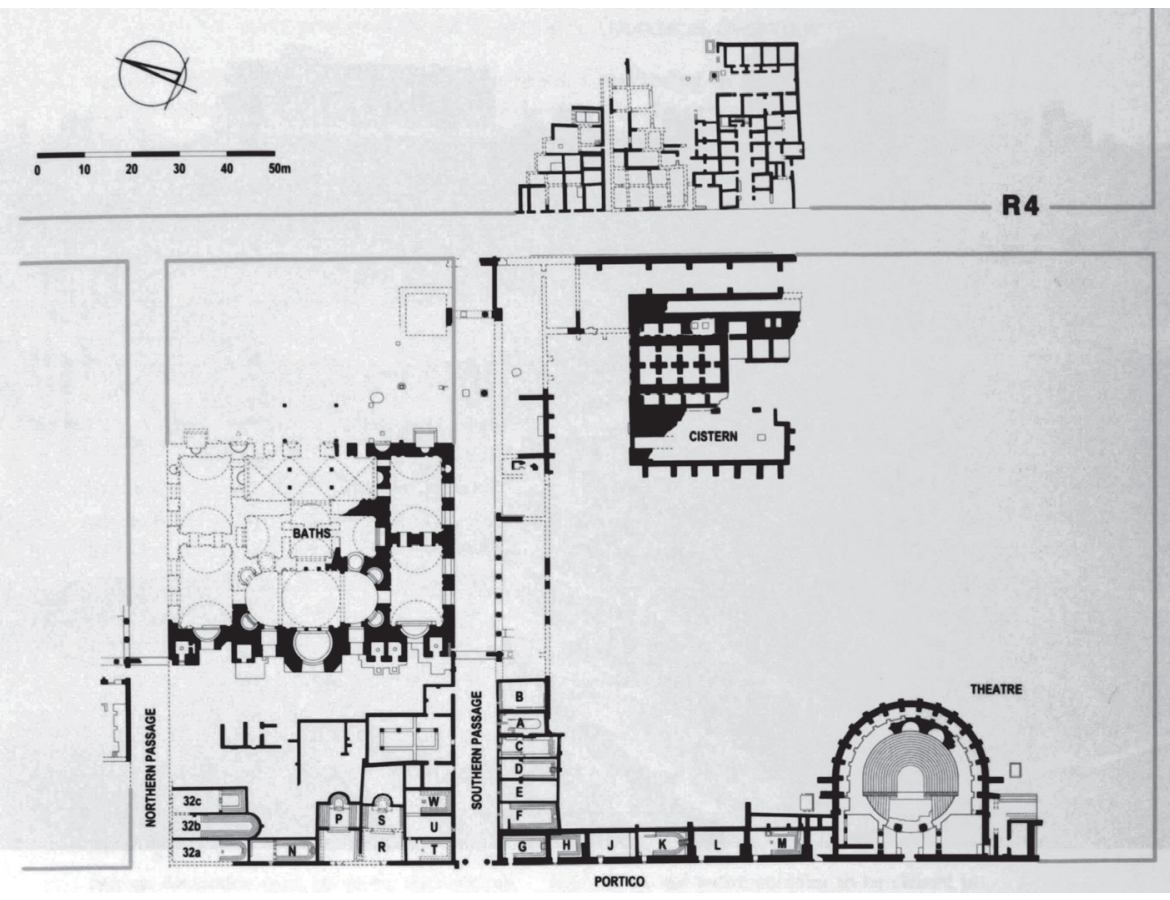

Figura 6. Planta general de Kôm el-Dikka, Alejandría (Majcherek 2007).

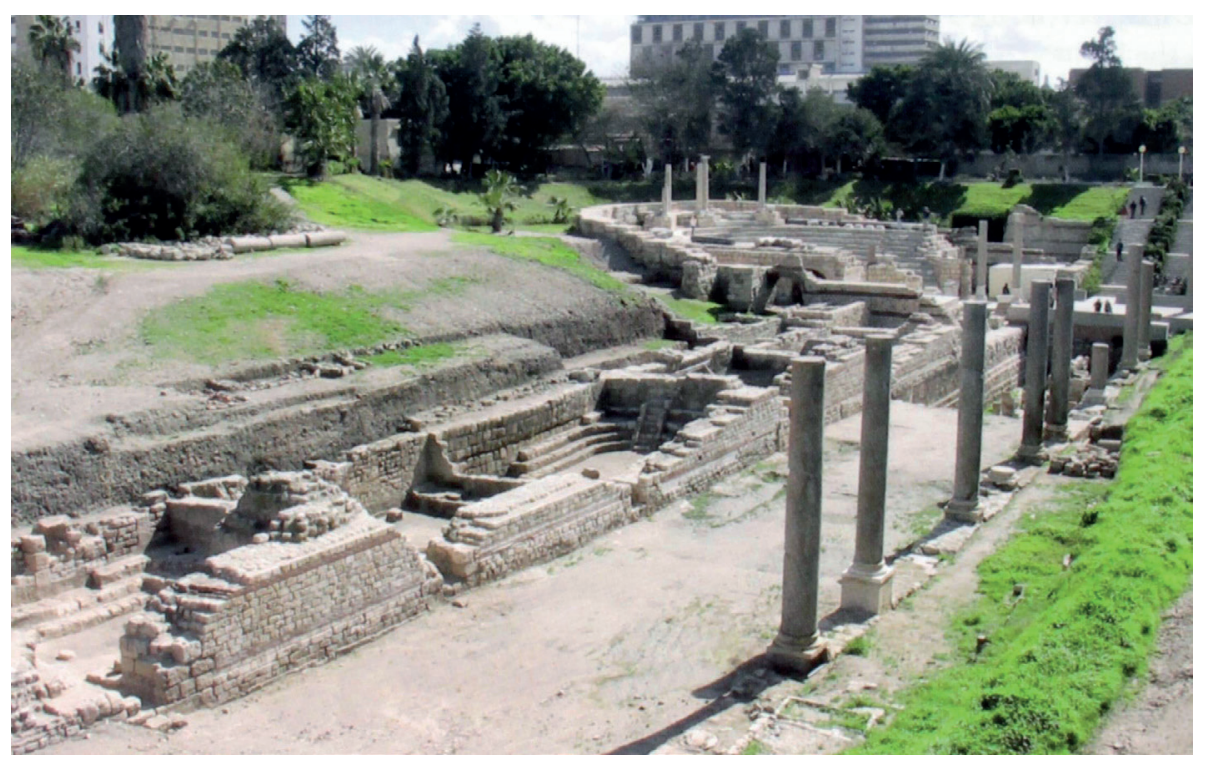

Figura 7. Pórtico y auditorios de Kôm el-Dikka (Majcherek 2007). 
Un precedente del auditorium de Constantinopla, así como de las escuelas de Beirut y de Alejandría, podría haberse fraguado en la propia Roma del siglo II d.C. Cuando el Athenaeum del emperador Adriano únicamente era abordable desde los análisis textuales, se le suponía una estructura teatral o anfiteatral, donde se desenvolverían la variedad de actividades académicas y culturales, las recitaciones agonales, sin dejar en el tintero las reuniones de naturaleza pública, fueran actos judiciales o asambleas senatoriales ${ }^{103}$. Pero en 2007 las obras del metro de la ciudad han trasladado el discurso a la arqueología, al dejar al descubierto tres auditorios prácticamente gemelos ${ }^{104}$ al oeste del Foro de Trajano, en el área de la Piazza della Madonna di Loreto (adyacente a Piazza Venezia). Fechados por la datación consular de sus ladrillos entre el 123 y el 125 d.C., y compuestos de dos graderíos enfrentados, enseguida se les adjudicó una funcionalidad cultural, en principio el de una biblioteca, a pesar de la ausencia de algunos de los elementos determinantes de estas construcciones ${ }^{105}$, y a día de hoy parece inevitable desligar los vestigios de la céntrica plaza romana del Ateneo fundado por el emperador filoheleno ${ }^{106}$. Roberto Egidi califica al conjunto de un "microcosmos universitario" enclavado en un sector de relieve político, institucional e intelectual de la urbe ${ }^{107}$. Aún en los siglos IV y V continuaba activo, al menos en sus cometidos judiciales, y en esa misma cronología, las evidencias epigráficas testifican que en los cercanos foros de Trajano y de Augusto, rectores y gramáticos se hacían cargo de sus estudiantes (se citan los atria Traiani y una schola), tal vez en sus exedras ${ }^{108}$. Tampoco se ha de olvidar la presencia en los alrededores de la Biblioteca de la Basílica Ulpia: Coarelli pone en duda la noticia de que sus libros hubiesen sido reubicados en las Termas de Diocleciano, y en general todo el área foral debía gozar de un buen estado de conservación, en razón de los elogios de Constancio II durante su visita del 357 d.C. y de la prolongación de su utilización hasta finales del siglo $\mathrm{V}^{109}$. En efecto, en época tardoantigua la zona en donde se encontraba el supuesto Ateneo reflejaba la palpitante vitalidad de la comunidad

${ }^{103}$ E. Hårleman, “Questions sur l'Athenaeum de l'empereur Hadrien”, Eranos 79 (1981) 63. Aprovecho para agradecer a Antonio López García, quien en 2014 se ha doctorado con una Tesis acerca del Ateneo de Adriano, la bibliografía que me ha facilitado y sus sugerencias acerca de la historia de esta edificación.

${ }^{104}$ Uno de ellos excavado con precedencia, en la década de 1930.

${ }^{105}$ A. Claridge, "Hadrian's lost Temple of Trajan", JRA 20 (2007) 76 ss

${ }^{106}$ R. Egidi, "L'area di Piazza Venezia. Nuovi dati topografici", R. Egidi, F. Filippi, S. Martone (eds), Archeologia e infrastrutture. Il tracciato fondamentale della linea C della metropolitana di Roma: prime indagini archeologiche. Bollettino d'Arte. Volume speciale (Roma 2010) 112 y ss. El mismo autor introduce diversas tesis surgidas antes y después de las excavaciones de la Piazza della Madonna di Loreto referidas a la pertenencia o no de las estructuras emergidas al Athenaeum, así como la posibilidad de identificarlo con otras edificaciones de Roma. R. Egidi, “L'Athenaeum di Roma”, R. Hidalgo, P. León (eds.), Roma, Tibur, Baetica. Investigaciones adrianeas (Sevilla 2013) 88-90.

${ }^{107}$ Ibid. 116.

${ }^{108}$ H.-I. Marrou, "La vie intellectuelle au forum de Trajan et au forum d'Auguste", MEFR 49 (1932) 93-110.

${ }^{109}$ F. Coarelli, Roma (Roma 2001) 145 y 302. 


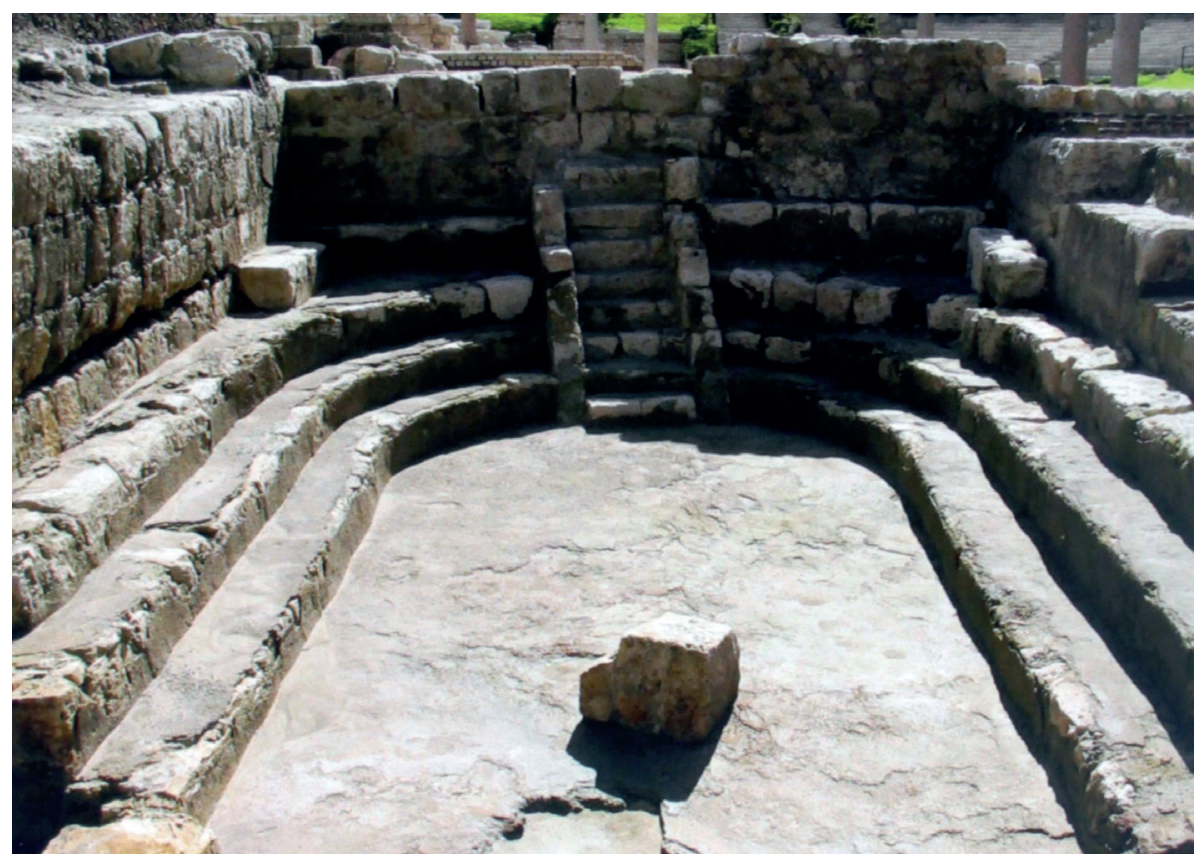

Figura 8. Auditorio K (McKenzie 2007).

estudiantil internacional que recalaba en Roma, y que el decreto del 370, aludido atrás, procedía a supervisar. Puesto que el pretendido complejo del Athenaeum no se ha sacado a la luz en su totalidad, podría todavía deparar más sorpresas, y corroborar o desmentir si como tipología arquitectónica se juzgó idónea su reproducción en el extremo oriental del Mediterráneo.

En la lectura pública de un himno que Apuleyo había compuesto en honor de Esculapio, realizada en el teatro de Cartago, el autor recordaba a los asistentes que en ese mismo entorno, en otras ocasiones, el funámbulo se jugaba la vida, el cómico despertaba las carcajadas con sus diálogos, el trágico recitaba y el mimo escenificaba sus fantasías. Así que los exhortaba a que cuando escuchasen salir de su boca palabras eruditas, se imaginaran transportados a la biblioteca de la ciudad, al igual que si su discurso les parecía dotado de dignidad, se sintieran como si se hallaran sentados en la curia ${ }^{110}$. La llamativa ficción sugerida por Apuleyo no tenía nada de descabellada, dado que sus oyentes sabrían que en uno y otro recinto actos similares podían tener lugar. Los espacios edilicios y monumentales de la ciudad romana conservaron usos polivalentes. De ello sacaron provecho profesores y alumnos: de éstos decía Libanio que tenían la costumbre de ensayar sus discursos en corrales de gallos, y San Agustín que repasaban sus ejercicios de retórica en el foro, porque de cualquier rincón de las urbes se

\footnotetext{
${ }^{110}$ Apul. Flor. 18.4-9.
} 
servían sus habitantes ${ }^{111}$. Como he pretendido mostrar, sofistas y filósofos reunían a sus pupilos en una serie de construcciones formalmente adecuadas para el propósito docente, aunque a menudo su función principal se reservara a otros cometidos. Esta constante se mantuvo desde principios de la época imperial y todavía se confirmaba en los siglos tardíos: se ha comprobado, por ejemplo, en la Antioquía de Libanio y en Alejandría. En ella, el Serapeum, entendido desde el punto de vista de la formación intelectual pagana, sobrevivió hasta la última década del siglo IV, mientras que pasados cien años, Zacarías Escolástico daba noticia de los frecuentes parlamentos de poetas, retóricos y gramáticos en el templo de las Musas $^{112}$. Estos centros se hallaban a disposición de los maestros en posesión de una cátedra de financiación pública, ya que los que como la filósofa Hipatia eran ajenos a estos honores, instruían a su choros en su casa ${ }^{113}$. Muy interesante me resulta la viabilidad de que los poderes municipales e imperiales, conforme a que la educación iba ocupando su lugar en la agenda de la política cultural del Estado, señalasen a sus profesores "contratados" nuevos ambientes donde acomodar sus clases, auditorios del estilo de los de Kôm el-Dikka y los que las fuentes refieren en Beirut y tal vez Constantinopla. Quién sabe si su arquitectura se articuló a partir de los auditoria asociados a las bibliotecas, o si su prototipo fue el Ateneo adrianeo.

${ }^{112}$ R. Cribiore, "Spaces for teaching in Late Antiquity", T. Derda, T. Markiewicz, E. Wipszycka (eds.), op. cit. 146.

${ }^{113}$ Ibid. 147. 